\title{
Findings From a Process Evaluation of an Indigenous Holistic Housing Support and Mental Health Case Management Program in Downtown Toronto
}

\author{
Michelle Firestone, Jessica Syrette, Teyohá:te Brant, Marie Laing, Steve Teekens
}

\section{A R T I C L E IN F O}

\section{Keywords:}

Urban Indigenous health

Program evaluation

Housing First

Mental health

Harm reduction

https://doi.org/10.32799/ijih.v16i2.33173

\section{A UTHOR INFO}

\begin{abstract}
A B S T R A C T
While urban Indigenous populations in Canada are increasing and represent many diverse and culturally vibrant communities, disparities between Indigenous and non-Indigenous people's experiences of the social determinants of health are significant. The Mino Kaanjigoowin (MK) program at Na-Me-Res (Native Men's Residence) in Toronto, Ontario, Canada, supports Indigenous men who are experiencing homelessness or are precariously housed and who have complex health and social needs. Using a community-partnered approach that aligns with wise practices for conducting Indigenous health research, a mixed-methods process evaluation of the MK program was conducted in 2017-2018 by the Well Living House in partnership with Na-Me-Res. Thematic analysis of qualitative data gathered through two focus groups with community members who access the MK program $(n=9)$ and key informant interviews with staff $(n=11)$ was carried out using a decolonizing lens. Results indicate that the MK program provides a unique healing model that is grounded in trust, honour, and respect. Strengths of the program include a harm reduction framework, meeting basic needs, and person-centred care. The program could be enhanced through increased human resource capacity and improved infrastructure, including a separate space for MK staff and activities. The evaluation findings demonstrate how the MK program provides specialized and culturally safe services as a bestpractice model to meet the complex health and social needs of urban Indigenous people.
\end{abstract}

Michelle Firestone, PhD, Research Scientist, St. Michael's Hospital, Toronto, Ontario, Canada. Email:

Michelle.Firestone@unityhealth.to

Jessica Syrette, Research Coordinator, Well Living House, St. Michael's Hospital

Teyohá:te Brant, Research Assistant, Well Living House, St. Michael's Hospital

Marie Laing, MA, Research Coordinator, Well Living House, St. Michael's Hospital

Steve Teekens, Executive Director, Native Men's Residence, Toronto, Ontario, Canada

V OLUME 16 , IS S UE 2, $2021 \bullet 139$ 


\section{Acknowledgements}

This research was funded by a grant from the Ontario Trillium Foundation. The project was undertaken in partnership with the staff and members of the Mino Kaanjigoowin program at Na-Me-Res (Native Men's Residence). The authors would also like to acknowledge the contributions from Elder Vern Harper and Gokoomis Jacque(line) Lavalley who shared their wisdom and spirit with this project and community.

\section{Introduction}

In the context of Canada's ongoing colonization of Indigenous Peoples and persistent impacts of historical trauma, Indigenous communities suffer from elevated burdens of mental health conditions and substance use disorders (Firestone et al., 2015; National Inquiry into Missing and Murdered Indigenous Women and Girls, 2019; Reading \& Wien, 2009). Over 85\% of the Indigenous population in Ontario live in urban settings (Ontario Ministry of Indigenous Affairs, 2018), making ongoing disparities in social determinants of health such as food insecurity, poverty, unemployment, and inadequate housing pressing issues for cities. In Toronto, Indigenous people are overrepresented in the homeless population, accounting for $1.5 \%$ to $2.5 \%$ of city residents but $16 \%$ of those experiencing homelessness, according to a recent point-in-time count (City of Toronto, 2018). Within the Canadian context, Indigenous homelessness is inextricable from ongoing dispossession from territories, intergenerational trauma, systemic racism, and high rates of child apprehension (Anderson \& Collins, 2014; Bingham et al., 2019; Patrick, 2014; Thistle, 2017). Overrepresentation of Indigenous people among urban homeless populations must be understood in relation to these symptoms rooted in colonial systems.

Studies including the Toronto Aboriginal Research Project (TARP) have highlighted how issues like systemic racism, addictions and substance use, and a lack of accessible, safe, and suitable housing are at the root of high levels of homelessness among Indigenous people in Toronto (McCaskill et al., 2011). In this context, housing, mental health, and addictions services that address both colonial trauma and Indigenous communities' resilience to thefts of land, language, and culture stand to make significant interventions in patterns of poor mental health and housing outcomes. Research with Indigenous people experiencing homelessness in Toronto has consistently named housing and addictions services that are abstinence-based as a barrier to access (McCaskill et al., 2011) and has pointed to the importance of culturally relevant social and health supports (Jim Ward Associates, 2008).

Na-Me-Res (Native Men's Residence) was founded in 1985 as an emergency shelter for Toronto-based Indigenous men (Na-Me-Res, n.d.). Na-Me-Res is committed to supporting Indigenous men in Toronto lead healthy, self-determined lives by meeting the mental, spiritual, and emotional needs of their members wherever they are on their journey. Currently, Na-Me-Res housing programs include a 71-bed emergency shelter; Sagatay, a nationally recognized transitional housing program; O'Gitchidaa Mushkiki Wigwam, a long-term independent housing initiative; and the Mino Kaanjigoowin (MK) program. 
The MK program was developed by Na-Me-Res in 2008 to serve Indigenous men who are experiencing homelessness or are vulnerably housed and who have diagnosed mental health conditions and complex social needs. Mino Kaanjigoowin means "finding the good to change yourself or your direction in life" in the Ojibwe language. The goal of the MK program is to assist members with locating and securing appropriate, stable housing and to provide culturally safe case management, nursing, and psychiatric care. The MK program follows a Housing First model. The Housing First model provides secure, permanent housing and case management to people experiencing homelessness as well as mental illness, without requiring abstinence from substance use (Tsemberis, 2012). Program components such as landlord advocacy, rental subsidies, and donations of home furnishings are important pillars of the Housing First model (Baxter et al., 2019). In order to maintain housing, the MK members sign a "Good Neighbour" agreement and have biweekly check-ins with case managers, and case managers develop relationships with landlords.

The program operates through a harm reduction framework and uses a holistic lens that addresses spiritual, physical, mental, and emotional balance. The MK team consists of case managers, traditional Elders and teachers, a nurse with expertise in mental health disorders, and a psychiatrist who is on site at Na-Me-Res.

In February 2017, Na-Me-Res, in partnership with the Well Living House (WLH), secured funding to conduct an evaluation of the MK program to assess the program delivery model and its approach to providing culturally safe, relevant, and sustainable housing supports and mental health services for Indigenous populations. WLH exists to conduct cutting-edge, Indigenous-led, community-partnered, applied health research with the goal of nurturing places and spaces where Indigenous communities can thrive. WLH is governed by a collaborative research memorandum of understanding between St. Michael's Hospital and a Counsel of Grandparents (WLH, n.d.). Researchers from WLH conducted a process evaluation focused on underlying values, service delivery approach, and model of care provided by the MK program, with the intent to provide meaningful, policy-relevant recommendations for moving forward.

\section{Methods}

It is critical that Indigenous-led and Indigenous-controlled organizations actively participate in the governance, design, implementation, and translation of Indigenous health service and program evaluation (Firestone et al., 2020; Johnston-Goodstar, 2012; LaFrance, 2004). This evaluation project was a unique opportunity for Indigenous organizations to lead and design their own locally relevant and feasible evaluation of Indigenous programs and services, contributing to self-determination at the individual and community level.

Using a community-partnered approach that aligns with wise practices for conducting Indigenous health research and evaluation (Cavino, 2013; Firestone et al., 2020; LaFrance \& Nichols, 2010) and builds on existing relationships with Na-Me-Res, WLH implemented a mixed-methods process evaluation of the MK program. Through initial engagement and inperson meetings, Na-Me-Res and WLH established governance processes and protocols, 
including a memorandum of understanding to guide and inform the work. WLH upholds Indigenous ethical standards that ensure balanced relationships between Indigenous and allied community research partners, academics, and additional stakeholders throughout the research process, while maintaining rigour and policy relevance. Approval from the Research Ethics Board at St. Michael's Hospital was also obtained.

Through a process evaluation framework, we investigated the unique program model of the MK program and how contextual factors shape its delivery (Moore et al., 2015). We explored the reach and coverage of the MK program, how staff and members interact with the MK program, which supports are needed, and why they are needed.

\section{Data Collection}

Process evaluation often requires a combination of quantitative and qualitative methods, allowing for the identification and in-depth exploration of complex and diverse pathways (Carroll et al., 2007; Smylie et al., 2011). Quantitative MK client administrative data were obtained from client records from 2014 to 2018. This article primarily discusses the qualitative data, using quantitative results only to provide sociodemographic characteristics of the members of the MK program's operations. A full description of the evaluation can be found at welllivinghouse.com.

Key informant interviews and focus groups were administered to gather qualitative data from both program staff and members. MK program staff were recruited through purposeful sampling for the key informant interviews $(n=11)$. Current and recent (within the past 2 years) members of the program were eligible to participate in focus groups and were recruited using information posters $(n=9)$. Interviews and focus groups were held between during the Fall and Winter of 2017-2018. Interviewees and focus group participants received an honorarium for their participation.

\section{Data Analysis}

Qualitative data were analyzed using thematic content analysis (Vaismoradi et al., 2013) through a critical decolonizing lens (Kovach, 2009; Smith, 2012; Smylie, 2011). This lens examines ongoing power structures that reinforce the marginalization of Indigenous people and ultimately lead to inequitable experiences. This decolonizing lens actively seeks to prioritize Indigenous worldviews. Members of the research team (JS, TB) each coded interview transcripts separately and compared themes to build consensus and create a codebook. When all the interviews were coded, the research team (MF, JS, TB, ML) met to discuss and finalize each code. The research team (MF, JS) also facilitated a feedback session with participants from the two focus groups. A total of seven people attended this session. A short explanation of the strengths and challenges of the MK program was presented. During this session, we provided participants with an opportunity to expand on themes and to provide any additional details or experiences they wished to share. 


\section{Results}

\section{Sample Characteristics}

At the end of 2018, there were 24 MK members actively receiving case management and supports through the program. The majority of active members fall between the ages of 30 and 50 years. At the time of intake, most of the 24 active MK members were either homeless $(n=5)$, or staying in emergency shelters $(n=5)$ or in social housing $(n=5)$. Two thirds of active MK members experienced positive housing outcomes during their involvement with the program by transitioning to a more stable form of housing (e.g., transition from shelter to social housing, or from social housing to private market). Of the $13 \mathrm{MK}$ members who were able to secure private housing, nine members receive ongoing rental supplements through the program.

\section{Thematic Analysis}

Thematic analysis revealed 11 program strengths, as well as areas for improvement. Here, we focus on five of the most salient themes expressed by MK staff and members: how MK meets members' basic needs and four aspects of the unique MK healing model-culture, having someone to count on, harm reduction, and honour. These five themes represent the experiences and concepts that were described most often by the participants.

\section{Meeting Basic Needs of Members}

Meeting the housing needs of MK members was frequently noted by staff as essential to trust-building and members' overall well-being. MK focus group members spoke about the vulnerability of life on the street coupled with the unsafe and unstable Toronto shelter conditions, and expressed the value of finding stable, safe, and accessible housing.

The MK program also teaches skills for living independently. These include cleaning and caring for an apartment, grocery shopping, budgeting, healthy cooking, and doing laundry. The MK program offers employment training, job counselling, literacy, and business training. Psycho-educational supports are available to members of the MK program through Na-Me-Res. The MK program meets the health care needs of its members by providing an on-site nurse and psychiatrist who work with case managers to develop health care plans. Traditional Indigenous health care is provided when possible. For some members, this brings otherwise inaccessible mental health care within reach:

Right now I'm working with a mental health worker. [I] was supposed to see a psychiatrist a long time ago, but now I'm starting to get into it and open it up. And it's starting to help a lot because there's also a doctor that comes here once a week for free-otherwise, I'd be paying somewhere else which I don't have the money for. I would have probably never tried to even take care of my mental health in that way otherwise. (Focus group participant)

In addition to meeting members in their homes and out in the community, MK staff assist their members with transportation for errands, appointments, and outings. Community members 
highlighted the value of this program element in bridging mobility gaps due to lack of reliable transportation and inaccessible living locations.

I think one of their strongest points of the program is that they ... they're mobile, right. They're just wherever the client is, they'll find them. If they are at another shelter they'll go to the other shelter, if they're in housing they'll go to housing, if they're in here, they'll come here. I think that's working very well. (Key informant)

\section{Healing Model}

Staff spoke very highly of the healing model offered though the MK program. MK offers a remarkable opportunity to build relationships and repair trust between the member and the provider through flexible assessment periods and pacing. Management and staff recognize that many members are deeply affected by trauma. Establishing trust is therefore built into the care plan in order to foster the mental and spiritual well-being of members. The program's health care team is not pressured to push people through the system of assessments and prescriptions. This allows the member to tell their stories, establish respect, and ultimately develop a unique care plan in which they are invested. The staff continually revisits goals and reassesses progress with members.

Most of the time my job is to screen for everything wrong. ... If I can just take the time to really explore someone's strengths, how it gives me greater respect for that person. And how much that then informs how I ask questions and talk to people. And I know it's a pressure within the system to not do that. But there's something very meaningful about getting to do that here. (Key informant)

Indigenous Cultures. Access to Indigenous cultures through medicines, ceremony, and Elders is available to all MK members. Cultural activities such as beading, drumming, sweats, and powwows are also offered through external programming. Some members and staff spoke to the importance of Indigenous staffing. Relationships with Indigenous staff are enriched through the shared understanding and experience of political issues, resilience, and identity. Connecting community members to themselves and others through culture can be crucial to healing and is a unique aspect of the MK program. One member described the importance of cultural programming:

There's a lot of stuff like the drums, the classes, you can come and do a sweat, beading classes, and different things about making medicines, traditional medicines and herbs. ... I'm definitely looking forward to stuff like this because me, I've had mental health [challenges] my whole life and I never wanted to take pharmaceutical drugs, so I've seen Elders and looked into more traditional healing and medicine and stuff like this. So it's definitely a big plus when you hear that they have classes to make your own medicines and eventually you could teach somebody else and make some at home, you know, teach your kids later in life. (Focus group participant) 
Having Someone to Count On. MK staff and members often develop close relationships. These relationships are the foundation of the MK program care model. Key informants explained how staff often feel like a surrogate family for members. Members expressed that the team's welcoming, responsive attitudes boost their spirits, while staff noted how taking the time for relationship-building boosts members' self-esteem and leads to successful implementation of care plans. The case management team builds strong, supportive, person-centred care plans that allow members to direct their healing journey and move forward at their own pace. Case workers link members with community services and programs to build a stronger network of care. The team assists members navigating legal, medical, education, and housing systems, often through advocacy and accompaniment. One member explained the importance of such strong relationships:

It's contact with your Elders. Contacts are really important to maintain, which includes Elders, it includes family, it includes doctors. ... It keeps you strong. It keeps you motivated. It's a medicine in itself, really, contacts. (Focus group participant)

MK staff try to disrupt the cycle in and out of shelters by identifying the members who have been discharged for mental health and/or substance use reasons and connecting them to other resources. This extends beyond services that are accessible in Toronto (e.g., to out-of-city treatment programs). This commitment to creating a safety net for the members is fundamental to MK case management. Members expressed the importance of having something to count on:

I choose to be a part of the MK because I know that when I'm down and out, that I have someone I can call, other than emergency help lines or doctors, someone that actually knows where I've been, how I live, and they're there for me right away. (Focus group participant)

Harm Reduction. Staff and members described harm reduction as a core element of the accessibility of MK. The MK program provides support to Na-Me-Res shelter clients who were discharged due to substance use. MK's Indigenous Elders explained that the MK harm reduction model uses traditional values of noninterference. This approach allows community members to set their own goals around substance use while progressing through their care plans.

It's a harm reduction program ... and that's the only reason I'm on it. (Focus group participant)

A couple of times I've almost lost my housing because of my substance abuse. Then I had to have a meeting with the MK staff at my building. But I've been going into bad withdrawal. They let me leave a couple of times. Go back to my apartment and have a couple of drinks so I don't have a seizure. That's harm reduction. (Focus group participant) 
Honour. Central to the MK program model are traditional Indigenous values. The MK staff work toward stabilizing their members and ensuring members' voices are respected, while members determine their own needs. Some members may not be seeking housing, so staff work on creative ways to ensure the safety and stability of those community members. Members spoke highly of this approach, explaining that it doesn't "set them up to fail" because it honours their choices, with MK staff customizing each member's care plan. The staff build increasing responsibilities into these plans (e.g., maintaining their residence, reducing harm to themselves) at a pace that suits the member. One member described the benefits of this customized approach:

That's the reason I'm in MK and they looked at my issues and said, "Yeah, you're a good candidate for this kind of program." Because if there wasn't that kind of program, I don't think I would be able to maintain it. I wouldn't have the support and I wouldn't look at myself as a worthwhile person. ... But now that they're there and saying, "Yes, you're a worthwhile person and we're going to look after you." And it helps feel good about that. (Focus group participant)

\section{Areas of Improvement}

Two key areas for improvement for the MK program are increased space and an increased number of staff. The MK program currently shares space with the Sagatay transitional housing residence. Staff and members spoke of the challenges due to the two programs' different approaches to substance use. MK members are unable to access on-site services and programs or visit their workers if they are using substances because Sagatay is an abstinence-based residence. The staff are creative in their solutions to meet with members; however, the lack of space leads to challenges (e.g., conversations in public spaces are limited for privacy reasons). These challenges can create familiar feelings of being denied care for members and can disrupt their healing.

Another challenge is that the MK case managers carry large caseloads. Due to the nature of intensive case-management work, it is imperative that staff have ample time to dedicate to each member. Staff and members reiterated that strong relationships between staff and members are paramount to the success of the program, and these relationships require time to build and maintain. Staff noted that both of these challenges are rooted in the lack of sufficient stable, long-term funding for the MK program.

\section{Limitations}

There were some limitations to this study. Due to the nature of the program, some MK members are difficult to contact and engage; our sample may not reflect those MK members whose mobility or health challenges may have prevented them from attending a focus group. In addition, given that our qualitative data collection occurred at one point in time, we may not have captured contextual factors or program elements that have changed over time. 


\section{Discussion}

The MK program provides stability, community, and culturally relevant supports to Indigenous men facing complex mental health and housing challenges in Toronto. This process evaluation uncovered program strengths as well as areas for growth and improvement.

At the core of the MK program's strengths are strong relationships between staff and members, and a commitment to honouring each member's individual healing journey. By providing stable and ongoing housing and mental health support to members, building connections to other health and social services, and fostering camaraderie among members, the MK program meets members' basic health and social needs. Of particular importance is the incorporation of Indigenous cultures into MK programming; this finding resonates with research suggesting that culture is a key modality of maintaining wellness for Indigenous people (Gone, 2013; Gray \& Cote, 2019; Rowan et al., 2014).

A defining pillar of the MK program is its harm reduction approach, which allows members to access services that are otherwise inaccessible due to abstinence-based programming and services in Toronto. The harm reduction approach, combined with access to diverse Indigenous ways of knowing and ceremony through other members of the program, staff, and Elders, supports members to choose their own path toward well-being and builds strength and resilience. Recent research and policy calls for an increase in harm reduction services for Indigenous people in Toronto, noting that harm reduction programming that is culturally responsive is especially important (Firestone et al., 2019; Speed \& Sault, 2019). As research has shown that the housing needs of urban Indigenous people in Canada are directly related to cultural loss and resurgence in the context of ongoing colonialism and erasure (Anderson \& Collins, 2014), the MK program demonstrates best practices for addressing the lived realities of Indigenous men experiencing homelessness in Toronto.

The evaluation of the MK program contributes to a growing body of evidence that links successful mental health and addiction treatment with integrated community- and culture-based approaches (Rowan et al., 2014). This study also adds to the existing literature exploring Housing First approaches to addressing urban Indigenous homelessness in Canada (Alaazi et al., 2015; Distasio et al., 2019).

Program challenges linked to lack of resources and infrastructure could be overcome through consistent funding and the recognition of self-determination of Indigenous health and social service systems. A key program recommendation is for the MK program to receive stable, long-term funding for its culturally safe, mobile team. Sustainable and dedicated resources would ensure that the MK program could expand its staff complement to meet growing demands, offer rent supplements and subsidies to more members, and secure a dedicated program space. As a best practice program model, the MK program has the potential to substantially reduce homelessness and increase stability for Indigenous men in Toronto. 


\section{Conclusion}

Indigenous men who are experiencing homelessness or who are precariously housed and facing complex mental health challenges receive person-centred supports, stability, and respect through the MK program. This evaluation reinforces the decades of positive impacts and lifesaving efforts made by Na-Me-Res and other Indigenous agencies in Toronto, while highlighting program elements that could be improved and areas that need increased resources. This collaborative research project has strengthened capacities and ongoing partnerships between Indigenous community organizations and stakeholders to improve health, well-being, and quality of life for Indigenous people living in Toronto.

\section{References}

Alaazi, D. A., Masuda, J. R., Evans, J., \& Distasio, J. (2015). Therapeutic landscapes of home: Exploring Indigenous Peoples' experiences of a Housing First intervention in Winnipeg. Social Science \& Medicine, 147, 30-37. https://doi.org/10.1016/j.socscimed.2015.10.057

Anderson, J. T., \& Collins, D. (2014). Prevalence and causes of urban homelessness among Indigenous Peoples: A three-country scoping review. Housing Studies, 29(7), 959-976. https://doi.org/10.1080/02673037.2014.923091

Baxter, A. J., Tweed, E. J., Katikireddi, S. V., \& Thomson, H. (2019). Effects of Housing First approaches on health and well-being of adults who are homeless or at risk of homelessness: Systematic review and meta-analysis of randomised controlled trials. Journal of Epidemiology \& Community Health, 73(5), 379-387. https://doi.org/10.1136/jech-2018210981

Bingham, B., Moniruzzaman, A., Patterson, M., Distasio, J., Sareen, J., O’Neil, J., \& Somers, J. M. (2019). Indigenous and non-Indigenous people experiencing homelessness and mental illness in two Canadian cities: A retrospective analysis and implications for culturally informed action. BMJ Open, 9(4), Article e024748. https://doi.org/10.1136/bmjopen-2018024748

Carroll, C., Patterson, M., Wood, S., Booth, A., Rick, J., \& Balain, S. (2007). A conceptual framework for implementation fidelity. Implementation Science, 2(1), Article 40. https://doi.org/10.1186/1748-5908-2-40

Cavino, H. M. (2013). Across the colonial divide: Conversations about evaluation in Indigenous contexts. American Journal of Evaluation, 34(3), 339-355. https://doi.org/10.1177/1098214013489338

City of Toronto. (2018). Street needs assessment 2018: Results report. https://www.toronto.ca/wpcontent/uploads/2018/11/99be-2018-SNA-Results-Report.pdf

Distasio, J., Zell, S., McCullough, S., \& Edel, B. (2019). Localized approaches to ending homelessness: Indigenizing Housing First. Institute of Urban Studies, University of Winnipeg. http://winnspace.uwinnipeg.ca/bitstream/handle/10680/1727/2019_IUS-Localized_Approaches_Ending_Homelessness_ENG_Final.pdf

Firestone, M., Maddox, R., O’Campo, P., Smylie, J., Bourgeois, C., Wolfe, S., Snelling, S., Manson, H., McKnight, C., Hebert, J., Boyer, R., II, Warry, W., \& van Wagner, V. (2020). 
Indigenous health service and program evaluation: Principles and guidelines from the "Three Ribbon" expert panel. Canadian Journal of Program Evaluation, 34(3), 413-424. https://doi.org/10.3138/cjpe.68831

Firestone, M., Smylie, J., Maracle, S., McKnight, C., Spiller, M., \& O'Campo, P. (2015). Mental health and substance use in an urban First Nations population in Hamilton, Ontario. Canadian Journal of Public Health, 106(6), e375-e381. https://doi.org/10.17269/CJPH.106.4923

Firestone, M., Syrette, J., Jourdain, T., Recollet, V., \& Smylie, J. (2019). "I feel safe just coming here because there are other Native brothers and sisters": Findings from a community-based evaluation of the Niiwin Wendaanimak Four Winds Wellness Program. Canadian Journal of Public Health, 110(4), 404-413. https://doi.org/10.17269/s41997-019-00192-6

Gone, J. P. (2013). Redressing First Nations historical trauma: Theorizing mechanisms for Indigenous culture as mental health treatment. Transcultural Psychiatry, 50(5), 683-706. https://doi.org/10.1177/1363461513487669

Gray, A. P., \& Cote, W. (2019). Cultural connectedness protects mental health against the effect of historical trauma among Anishinabe young adults. Public Health, 176, 77-81. https://doi.org/10.1016/j.puhe.2018.12.003

Jim Ward Associates. (2008). Dealing effectively with Aboriginal homelessness in Toronto: Final report. Retrieved from Homeless Hub website: https://www.homelesshub.ca/sites/default/files/attachments/biw3xtal.pdf

Johnston-Goodstar, K. (2012). Decolonizing evaluation: The necessity of evaluation advisory groups in Indigenous evaluation. New Directions for Evaluation, 2012(136), 109-117. https://doi.org/10.1002/ev.20038

Kovach, M. (2009). Indigenous methodologies: Characteristics, conversations, and contexts. University of Toronto Press.

LaFrance, J. (2004). Culturally competent evaluation in Indian Country. New Directions for Evaluation, 2004(102), 39-50. https://doi.org/10.1002/ev.114

LaFrance, J., \& Nichols, R. (2010). Reframing evaluation: Defining an Indigenous evaluation framework. The Canadian Journal of Program Evaluation, 23(2), 13-31. https://evaluationcanada.ca/secure/23-2-013.pdf

McCaskill, D., Fitz Maurice, K., \& Cidro, J. (2011). Toronto Aboriginal Research Project: Final report. Toronto Aboriginal Support Services Council. Retrieved from Toronto Council Fire Native Cultural Centre website: http://www.councilfire.ca/Acrobat/tarp-finalreport2011.pdf

Moore, G. F., Audrey, S., Barker, M., Bond, L., Bonell, C., Hardeman, W., Moore, L., O'Cathain, A., Tinati, T., Wight, D., \& Baird, J. (2015). Process evaluation of complex interventions: Medical Research Council guidance. BMJ, 350, Article h1258. https://doi.org/10.1136/bmj.h1258

Na-Me-Res. (n.d.). About Na-Me-Res. https://www.nameres.org/about/

National Inquiry into Missing and Murdered Indigenous Women and Girls. (2019). Reclaiming power and place: The final report of the National Inquiry into Missing and Murdered 
Indigenous Women and Girls. https://www.mmiwg-ffada.ca/final-report/

Ontario Ministry of Indigenous Affairs. (2018). The Urban Indigenous Action Plan. https://files.ontario.ca/uiap_full_report_en.pdf

Patrick, C. (2014). Aboriginal homelessness in Canada: A literature review. Homeless Hub Paper \#6. Canadian Homelessness Research Network Press. https://www.homelesshub.ca/sites/default/files/AboriginalLiteratureReview.pdf

Reading, C. L., \& Wien, F. (2009). Health inequalities and social determinants of Aboriginal Peoples' health. National Collaborating Centre for Indigenous Health. https://www.ccnsanccah.ca/docs/determinants/RPT-HealthInequalities-Reading-Wien-EN.pdf

Rowan, M., Poole, N., Shea, B., Gone, J. P., Mykota, D., Farag, M., Hopkins, C., Hall, L., Mushquash, C., \& Dell, C. (2014). Cultural interventions to treat addictions in Indigenous populations: Findings from a scoping study. Substance Abuse Treatment, Prevention, and Policy, 9(1), Article 34. https://doi.org/10.1186/1747-597X-9-34

Smith, L. T. (2012). Decolonizing methodologies: Research and Indigenous Peoples (2nd ed.). Zed Books.

Smylie, J. K. (2011). Knowledge translation and Indigenous communities: A decolonizing perspective. In E. M. Banister, B. J. Leadbeater, \& E. A. Marshall (Eds.), Knowledge translation in context: Indigenous, policy, and community settings (pp. 181-200). University of Toronto Press. https://doi.org/10.3138/9781442689961-014

Speed, S., \& Sault, M. (2019). Toronto Indigenous Overdose Strategy: Summary report. Retrieved from City of Toronto website: https://www.toronto.ca/legdocs/mmis/2019/hl/bgrd/backgroundfile-129421.pdf

Thistle, J. A. (2017). Definition of Indigenous homelessness in Canada. Canadian Observatory on Homelessness. Retrieved from Homeless Hub website: https://homelesshub.ca/sites/default/files/COHIndigenousHomelessnessDefinition.pdf

Tsemberis, S. (2012). Housing First: Basic tenets of the definition across cultures. European Journal of Homelessness, 6(2), 169-173.

https://www.feantsaresearch.org/download/ejh6_2_resp_housingfirst185255795414212777 7.pdf

Vaismoradi, M., Turunen, H., \& Bondas, T. (2013). Content analysis and thematic analysis: Implications for conducting a qualitative descriptive study. Nursing \& Health Sciences, 15(3), 398-405. https://doi.org/10.1111/nhs.12048

Well Living House. (n.d.). Welcome to Well Living House. http://www.welllivinghouse.com/ 